\title{
O CONTENCIOSO ADMINISTRATIVO EM PORTUGAL E NO BRASIL: UMA INFLUÊNCIA DO LIBERALISMO FRANCÊS DE
} 1789 ?

ADMINISTRATIVE LITIGATION IN PORTUGAL AND BRAZIL: AN INFLUENCE OF FRENCH LIBERALISM OF 1789?

\author{
Mariana AzeVedo Comello Oliveira*
}

RESUMO

O artigo investiga as influências históricas na construção do contencioso administrativo em Portugal: se suas influências se devem à Revolução Francesa de 1789 ou ao modelo absolutista que a antecedeu. Há, no texto, referência ao modelo brasileiro, inspirado no sistema inglês, que se afasta do modelo português, na sua formulação jurídica e, também, por não comungar das mesmas influências históricas. Ao retomar o Direito português, apresenta, num primeiro momento, a tese majoritariamente aceita pelos juristas: a de que esse contencioso tem origem nas ideologias advindas das chamadas revoluções liberais. Após, é apresentada uma antítese, com suporte no filósofo, sociólogo e político Alexis de Tocqueville, o qual encontra as raízes desse contencioso no regime absolutista, como um mecanismo estrategicamente desenvolvido pelo poder absoluto para conservar sob seu julgo as demandas de interesse do Estado.

Palavras-chave: Contencioso administrativo; Revolução Francesa; Liberalismo.

\section{ABSTRACT}

The article investigates the historical influences on the construction of administrative litigation in Portugal if their influences are due to the French Revolution of 1789 or the absolutist model that preceded it. Does the text, a reference to the Brazilian model, inspired by the English system, which departs from the Portuguese model both with regard to its legal formulation, but also does not share the latter with the same historical influences. When resuming the Portuguese law, presents, at first, the majority thesis accepted by jurists: that this litigation has its origin in ideologies stemming from so-called liberal revolutions. After, an antithesis, with the support philosopher, sociologist and politician Alexis de Tocqueville, who finds the roots of this litigation in absolutist regime as a mechanism strategically developed by absolute power to keep under your judge the demands of state interest is shown.

Keywords: Administrative litigation; French Revolution; Liberalism.

* Mestre em Ciências Jurídico-Políticas pela Faculdade de Direito da Universidade de Coimbra (Portugal). marianacataguases@gmail.com 
SUMÁRIO

INTRODUÇÃO; 1 A TESE - O CONTENCIOSO ADMINISTRATIVO COMO TENDO A SUA ORIGEM NAS REVOLUÇÕES LIBERAIS. A) O LIBERALISMO; B) AS ESCOLAS DO CONTENCIOSO ADMINISTRATIVO; C) O CONTENCIOSO ADMINISTRATIVO EM PORTUGAL; D) O CONTENCIOSO ADMINISTRATIVO NO BRASIL; 2 A ANTÍTESE - O CONTENCIOSO ADMINISTRATIVO TENDO SUA ORIGEM NO REGIME ABSOLUTISTA FRANCÊS (O ANTIGO REGIME); CONSIDERAÇÕES FINAIS; REFERÊNCIAS

\title{
- INTRODUÇÃO
}

\begin{abstract}
Vê-se que a história é uma galeria de quadros em que há poucos originais e muitas cópias. (...) Os homens de 1789 haviam derrubado o edifício, mas suas fundações permaneceram na alma dos que o destruíram; e sobre essas fundações foi possível reergue-lo novamente de uma só vez $e$ construí-lo mais sólido do que nunca antes ${ }^{1}$.
\end{abstract}

A pergunta colocada no início do texto não pode ser respondida, sem que antes o leitor passe por uma breve reflexão sobre um tema tão tumultuoso ${ }^{2}$ e complexo. Essa reflexão iniciase com a apresentação de uma tese, defendida majoritariamente pela doutrina do Direito Administrativo e, após, passa por sua antítese, defendida minoritariamente por Tocqueville. Ou seja, a pergunta revela um problema: o fundamento histórico e a finalidade prática do contencioso administrativo - numa perspectiva histórica, também - justificam as normas até hoje prescritas e aplicadas no Direito português e no brasileiro?

O texto epigrafado, já aponta o problema - o contencioso administrativo tem sua origem no edifício erguido após a Revolução francesa ou remonta às fundações que não foram destruídas pela revolução?

A resposta à indagação será apresentada pela autora em suas considerações finais após a abordagem das principais escolas do pensamento jurídico que tratam do problema, desenvolvidas quando a doutrina administrativista procurou soluções e propostas de normas práticas construídas em torno do contencioso administrativo -, acompanhada da sua justificativa e dos modelos idealizados. ${ }^{3}$

\footnotetext{
${ }^{1}$ TOCQUEVILLE, Alexis de. O Antigo Regime e a Revolução; Tradução de Rosemary Costhek Abílio. São Paulo: Editora WMF Martins Fontes. 2009. P. 74 e 80.

${ }_{2}^{2}$ MARCOS, Rui Manuel de Figueiredo. História da Administração Pública, Relatório sobre o Programa, o Conteúdo e os Métodos de Ensino. Coimbra: Editora Coimbra. 2005. P 81.

${ }^{3}$ A referência a modelos idealizados pelas escolas administrativistas do século XIX se justifica porque, enquanto modelos teóricos, buscavam explicar o sistema normativo, que é prático, simplificando a realidade e, portanto, não necessariamente foram introduzidas - as suas propostas e soluções - nos sistemas do Direito que vigoraram ou que ainda vigoram.
} 
No curso do artigo, a autora, visando a responder à questão problema apontada, colocada em diálogo o filósofo e político francês, Alexis de Tocqueville, com autores administrativas, assumindo a dialética como metodologia.

\title{
1 A TESE - O CONTENCIOSO ADMINISTRATIVO E A SUA ORIGEM NAS REVOLUÇÕES LIBE- RAIS. $^{4}$
}

Sobre as origens do contencioso administrativo, José Frederico Laranjo ${ }^{5}$, no final do século XIX, esclareceu que:

\begin{abstract}
A França, outras nações da raça latina, e nós uma d'ellas, têm quasi sempre tido desde as revoluções liberaes, com as exceções já indicadas da Itália desde 1864 e da Hespanha desde 1868, tribunaes administrativos especiaes; mas esses quasi nunca na segunda instância têm tido jurisdicção (...) Foi esse o estado da legislação em França até 1872; é esse ainda o estado da legislação entre nós. (...) A organização do tribunal do contencioso administrativo, mesmo sem jurisdicção, é pois mais liberal do que atribuir ao governo a decisão das questões administrativas e somente resta confrontar as vantagens da escola intermedia com as da escola radical. Foi o que fez a França, quando em 1872 deu ao contencioso administrativo da segunda e ultima instancia jurisdicção própria. ${ }^{6}$
\end{abstract}

As revoluções liberais, em referência no texto do jurista, são consideradas o ponto de irradiação de influências, que atingiram os sistemas jurídicos português e brasileiro. Vale sublinhar que esse centro de irradiação aconteceu na Europa, mas seus efeitos foram sentidos em outras partes do globo. Nesse ponto, sustenta-se nas ideias de Hobsbawm, segundo as quais se a perspectiva é europeia, é porque, nesse período, o mundo, ou pelo menos uma

\footnotetext{
${ }^{4}$ O subtítulo faz referência à Revolução Francesa de 1789 e a revolução industrial inglesa. A revolução inglesa não vem datada porque são várias as propostas históricas sobre a sua época. Historiadores mais antigos tenderam datar a revolução industrial de 1760. Mas uma investigação mais cuidadosa levou a maioria dos estudiosos a localizar como decisiva a década de 1780 e não a de 1760, pois foi então que, até onde se pode distinguir, todos os índices estatísticos relevantes deram uma guinada repentina, brusca e quase vertical para a partida. Entretanto, o historiador ainda explica sobre o termo "revolução industrial": o fato existia na Inglaterra antes do termo. Os socialistas ingleses e franceses - eles próprios um grupo sem antecessores - só o inventaram por volta da década de 1820, provavelmente por analogia com a revolução política na França. In Hobsbawm, Eric. J. A Era das Revoluções - 1789 - 1848. São Paulo: Paz e Terra. 2012. P. 58/59. Segundo Rui Manuel de Figueiredo Marcos, Inaugura-se, então, o ciclo imediato que, sob a inspiração dos ideais político-jurídicos da Revolução Liberal que eclodiu em 1820, se designa, precisamente, por período da Administração Liberal. In Marcos, Rui Manuel de Figueiredo. História da Administração Pública, Relatório sobre o Programa, o Conteúdo e os Métodos de Ensino. Coimbra: Editora Coimbra. 2005. P. 70.

${ }^{5}$ Deve-se a este autor a defesa pioneira, entre nós, do modelo do "Contencioso da Administração" confiado a Tribunais Administrativos dotados de competência decisória e de garantias de imparcialidade e inamobilidade. (Cfr. Maria da Glória Garcia, Da Justiça Administrativa em Portugal. Sua Origem e Evolução, cit, P. 534). In Costa, Mário Júlio de Almeira. Colaboração de Rui Manuel de Figueiredo Marcos. 5. Ed. Rev. e Atual. Coimbra: Almedina. 2011. P 512.

6 LARANJO, José Frederico. Princípios e Instituições de Direito Administrativo. Coimbra: Imprensa da Universidade. 1888. P. 35 e 38/39.
} 
grande parte dele, transformou-se a partir de uma base europeia, ou melhor, franco britânica. $^{7}$

Desse modo, pode-se compreender o porquê de no século XIX, o texto transcrito relacionar, no referente aos países latinos, a existência de Tribunais Administrativos ou de Tribunais Especiais - para julgar as contestações de direitos entre particulares e a administração, em matéria administrativa - às chamadas revoluções liberais. Segundo Tocqueville, em referência à Revolução Francesa especificamente, diz que tal revolução teve como único efeito abolir as instituições políticas que, durante vários séculos, haviam reinado soberanas sobre a maioria da população e que são chamadas de instituições feudais, para substitui-las por uma ordem social e política mais uniforme e simples que tinha como base a igualdade de condições. ${ }^{8}$ Dentre essas chamadas novas instituições políticas, com certa regularidade, está compreendido o Contencioso Administrativo. É a partir dessa consideração histórica que será apresentada a tese.

\section{a. O liberalismo:}

Sobre os ideais do liberalismo do século XVIII e do republicanismo, oriundos da revolução política da França, Ricardo-Velez, com suporte nos escritos de Necker (esse último, um dos integrantes do movimento conhecido como "os doutrinários", constituído por pensadores franceses que transportaram as ideias liberais da Inglaterra para a França), entende que uma Constituição republicana e liberal indubitavelmente atribui ao povo, assim definido, todos os direitos políticos que pode exercer ordeiramente. $O$ texto a seguir expressa as preocupações dos pensadores da França no período Napoleônico (após o 18 de Brumário), em relação ao que - para eles - seria uma verdadeira República (no sentido de pensamento liberal).

E se for verdade que este não existe dessa forma, se for verdade que na França a extensão do país ou o caráter dos habitantes se opusessem a isso, a boa fé exigiria que se chegasse a um acordo sobre o particular, exigiria que deixássemos de dar o nome de República a uma forma de governo na qual o povo não seria nada, nada mais do que uma ficção. ${ }^{9}$

Segundo Mário Júlio de Almeida Costa, esses ideais, contextualizados em França, e que refletem as preocupações com os diversos caminhos políticos, muitas vezes enviesados, percorridos pela sociedade francesa durante sua fase revolucionária, que se estendeu de 1789 a 1848 , são suprimidos, no pensamento europeu pelos movimentos da Contra-Revolução, do Romantismo e do Idealismo alemão. Mas, em um segundo momento, são novamente assumidos. E é precisamente essa influência - a do liberalismo iluminista - que atua sobre os juristas

\footnotetext{
${ }^{7}$ HOBSBAWM, Eric. J. A Era das Revoluções - 1789 - 1848. São Paulo: Paz e Terra. 2012. P. 13

8 TOCQUEVILLE, Alexis de. O Antigo Regime e a Revolução; Tradução de Rosemary Costhek Abílio. São Paulo: Editora WMF Martins Fontes. 2009. P. 23/24.

${ }^{9}$ RODRIGUES, Ricardo - Velez. O Liberalismo Francês: a tradição doutrinária e sua influência no Brasil. P 33. Disponível em: http://www.cdpb.org.br/liberalismo_frances_velez.pdf. Acesso em: 2.4.2014.
} 
do final do século XIX (José Frederico Laranjo, ao refletir sobre as escolas do que hoje denominamos contencioso administrativo, possivelmente, recebe essas influências). ${ }^{10}$ Esses ideais políticos são transferidos para o Direito de formas diversas, assumindo metodologias também diversas. Num primeiro momento, tais ideais são cristalizados na forma de direitos naturais, inalienáveis, como ilustra o enxerto a seguir:

Como não se desconhece, na base de toda a construção ideológica e filosofia do século XIX está o princípio de que o homem nasce dotado de certos direitos naturais e inalienáveis, e que a exclusiva missão do Estado - de raiz pactícia e sem fins próprios - é a promoção e salvaguarda desses direitos individuais e originários. ${ }^{11}$

Duas ideias andam muita próximas nesse modelo do Estado Liberal: o individualismo e o liberalismo econômico. O individualismo, em um plano político, resulta do princípio da soberania popular e nacional. ${ }^{12}$ No plano do Direito, resulta do dever do Estado de resguardar os direitos individuais e originários, que podem ser traduzidos pelas diferentes formas de liberdades. É a ideia da liberdade de todos e como meio indispensável para assegurá-la - a ideia de igualdade. ${ }^{13}$ No plano do liberalismo econômico, vê-se que, num primeiro momento, as construções da chamada escola dos fisiocratas, explicam e normatizam os limites da intervenção do Estado na ordem econômica e o necessário enfraquecimento das barreiras alfandegárias, com viés protecionista, que impediam a circulação de mercadorias e serviços para além das fronteiras políticas. Percebe-se, todavia, ainda no curso da história moderna, que os fisiocratas focaram seus estudos (tanto no plano positivo, quanto no normativo) nas atividades do primeiro setor (hoje assim chamado), ficando ligados, ainda, aos interesses fundiários e, por assim dizer, do Estado absolutista. São as ideias cunhadas pela Escola Clássica da Economia que realmente traduzem as ideias do liberalismo econômico, com as teorias de Adam Smith (1723 a 1790), David Ricardo (1772 a 1823) e Stuart Mill (1806 a 1873). ${ }^{14}$

No plano interno do Direito, aqui referente à sua própria metodologia, verifica-se algumas propostas que influenciaram o pensamento jurídico europeu no século XIX e que serão aqui expostas brevemente. Não há aqui uma preocupação de verticalizar o estudo da filosofia do Direito, mas de demonstrar as ideias que permeavam o ambiente jurídico no século XIX e que, em certa medida, influenciaram os juristas europeus, inclusive.

I. O positivismo jurídico:

Para essa escola jusfilosófica, o direito identifica-se com a lei; esta materializa ou positiva o direito ideal de inspiração racionalista; a ordem jurídica constitui um todo acabado; a

\footnotetext{
${ }^{10}$ Essas escolas serão apresentadas em tópico a seguir.

${ }^{11}$ COSTA, Mário Júlio de Almeira. Colaboração de Rui Manuel de Figueiredo Marcos. 5. Ed. Rev. e Atual. Coimbra: Almedina. 2011. P 512.

12 Para maior aprofundamento sobre o texto, ver, inclusive, Costa, Mário Júlio de Almeida. Colaboração de Rui Manuel de Figueiredo Marcos. 5. Ed. Rev. e Act. Coimbra: Almedina. 2011. Páginas 432 e seguintes.

${ }^{13}$ COSTA, Mário Júlio de Almeira. Colaboração de Rui Manuel de Figueiredo Marcos. 5. Ed. Rev. e Atual. Coimbra: Almedina. 2011. P 432.

${ }^{14}$ COSTA, Mário Júlio de Almeira. Colaboração de Rui Manuel de Figueiredo Marcos. 5. Ed. Rev. e Atual. Coimbra: Almedina. 2011. P 435.
} 
sua plenitude atinge o momento definido num conjunto de Códigos modernos, sistemáticos, completos - a razão escrita encontrada pelo poder legislativo omnipotente. ${ }^{15}$

Nas palavras de Castanheira Neves, no positivismo jurídico, o texto é compreendido não apenas em termos expressivos, mas constitutivos. A significação é associada (presa) ao texto e só no texto deve ser procurada. É deste modo que o positivismo legalista postula que a lei é seu texto, e implicará isso não só que o direito positivo se tenha por autossuficiente $e$ fechado em si (a excluir o recurso a critérios normativos além dele próprio para a sua determinação e realização) ${ }^{16}$. Nota-se nessas passagens e em momentos dos textos que a seguem, que, para o positivismo legalista, não há espaço para a hermenêutica, já que tal técnica levaria a uma mediação do texto legal, sendo essa considerada imprecisa, senão misteriosa. É nesse sentido que corresponde rigorosamente à escola da exegese (exegesis ou explicatio $e$, portanto, a mera explicitação). ${ }^{17}$

\section{A Escola Histórica do Direito.}

Possui, simbolizando a sua origem, a célebre polêmica que, no ano de 1814, contrapôs A. F. J. Thibaut (...) a F. C. Von Savigny. O primeiro defendendo a excelência de uma codificação do Direito para a Alemanha e o segundo a considerando inoportuna. ${ }^{18}$

O que está para além dessa discussão é a compreensão que Savigny tem sobre o Direito, como aspecto histórico da cultura humana, assim como os são a língua, a religião e as restantes expressões culturais. Logo, o "jurídico resulta de uma criação espontânea da consciência coletiva, de uma manifestação do espírito do povo. (...) E bem assim a sua transformação contínua em função das circunstâncias também peculiares de cada povo. (...)" Dessa construção, "decorre a supremacia do costume, dimanação imediata da comunidade, sobre a lei. (...)" ${ }^{19}$ Entende que o costume não cria, antes exterioriza o direito positivo. Também decorre que em face da constante evolução reconhecida ao Direito, se posiciona contra o movimento de codificação. ${ }^{20}$ É uma linha objetivista, se contrapondo ao subjetivismo do positivismo legalista. O objetivismo do historicismo explica-se porque esse quer enxergar o Direito historicamente contextualizado (que deve acompanhar as mudanças ocorridas na comunidade), independentemente da busca pela vontade do Legislador. A preocupação com a separação dos poderes (funções do Estado) não é tão forte como a que é encontrada nas linhas subjetivistas, que se preocupam em encontrar a vontade do legislador, expressa nos textos legais.

\footnotetext{
${ }^{15}$ COSTA, Mário Júlio de Almeira. Colaboração de Rui Manuel de Figueiredo Marcos. 5. Ed. Rev. e Atual. Coimbra: Almedina. 2011. P 437.

16 NEVES, A. Castanheira. Metodologia Jurídica. Problemas Fundamentais. Reimpressão. Coimbra: Coimbra Editora. 2013. P. 96/97.

17 NEVES, A. Castanheira. Metodologia Jurídica. Problemas Fundamentais. Reimpressão. Coimbra: Coimbra Editora. 2013. P. 96/97.

${ }^{18}$ COSTA, Mário Júlio de Almeira. Colaboração de Rui Manuel de Figueiredo Marcos. 5. Ed. Rev. e Atual. Coimbra: Almedina. 2011. P 439.

${ }^{19}$ COSTA, Mário Júlio de Almeida. Colaboração de Rui Manuel de Figueiredo Marcos. 5. Ed. Rev. e Atual. Coimbra: Almedina. 2011. P 440/441.

${ }^{20}$ COSTA, Mário Júlio de Almeida. Colaboração de Rui Manuel de Figueiredo Marcos. 5. Ed. Rev. e Act. Coimbra: Almedina. 2011. P 440/441.
} 
III. Pandectística. Jurisprudência dos conceitos.

A Pandectística ${ }^{21}$ possui como objetivo reunir todo o universo jurídico de forma sistemática e abstrata ${ }^{22}$. Segundo Mário Júlio de Almeida Costa, verifica-se nessa escola:

O retorno a um novo positivismo, aceitando-se, afinal, um critério que não está longe do adoptado pelo jusracionalismo. Com simples perspectiva científica, procura-se edificar um sistema dogmático completo e fechado, onde se encontraria resposta para todos os problemas jurídicos. Só que se esquecia a dinâmica iniludível das realidades político-econômicas, sociais e culturais. ${ }^{23}$

Essa escola está ligada à criação de uma extensa dogmática jurídica do direito privado. O Pandectísmo, em sua caracterização metodológica, está ligado à jurisprudência dos conceitos. Por esse método de compreensão e aplicação do Direito, as soluções individuais são dedutíveis dos princípios, aos quais as mesmas estão subsumíveis (são deduzidas logicamente: o problema individual é subsumido a uma norma geral e abstrata, a um conceito, e a conclusão é uma regra para o caso individual). O seu método jurídico é a operação da lógica formal. Propõe um encadeamento de espécies e subespécies de conceitos, desde a base até o vértice do sistema, a ciência do Direito opera ignorando a relevância das valorações extra-jurídicas. (...) Ficava de fora, em suma, toda a explicação prática das soluções legais. ${ }^{24}$

Larenz reduz essas construções do século XIX à seguinte ideia:

(...) que em regra se julga ainda não só com o dever, mas com o poder de revelar a razão mais ou menos oculta na lei, de libertar cada norma da lei do seu isolamento empírico, de a depurar, digamos, reconduzindo-a a um princípio superior ou a um conceito geral, e promover, deste modo, a espiritualização do "positivo"- propósitos em que a servem, ao lado da interpretação lógica e da interpretação sistemática, tanto a elaboração dos conceitos. ${ }^{25}$

Essa explanação sobre as escolas que pretenderam compreender o Direito e aplicá-lo no século XIX é importante nesse trabalho para o entendimento sobre como os valores do liberalismo desse século, calcados no princípio da separação dos poderes do Estado, são utilizados pela tese majoritária para explicar a existência e a estrutura de funcionamento do contencioso da Administração. Ou melhor, as escolas apresentadas nesse trabalho, construídas

\footnotetext{
${ }^{21}$ Relativo ao Digesto, fonte das construções dogmáticas do Direito Germânico para essa escola, no século XIX. Disponível em http://www.rbdc.com.br/RBDC/RBDC-07/revista07-vol1.pdf\#page=31. Acesso em 18.04.2014.

${ }^{22}$ COSTA, Mário Júlio de Almeida. Colaboração de Rui Manuel de Figueiredo Marcos. 5. Ed. Rev. e Act. Coimbra: Almedina. 2011. P 442.

${ }^{23}$ COSTA, Mário Júlio de Almeida. Colaboração de Rui Manuel de Figueiredo Marcos. 5. Ed. Rev. e Act. Coimbra: Almedina. 2011. P 442.

${ }^{24}$ COSTA, Mário Júlio de Almeida. Colaboração de Rui Manuel de Figueiredo Marcos. 5. Ed. Rev. e Atual. Coimbra: Almedina. 2011. P 443/444.

${ }^{25}$ LARENZ, Karl. Metodologia da Ciência do Direito. Tradução de José Lamego. 3 ed. Lisboa: Fundação Calouste Gulbenkian. 1997. P. 40.
} 
ao longo do século XIX, revelam uma preocupação com a construção de uma dogmática administrativista que não colida com um princípio do liberalismo que lhe é muito caro - a separação dos poderes (funções) do Estado - e que influenciou um sistema de controle da legalidade da atividade administrativa dentro do próprio Poder Executivo. Assim, o sistema jurídico deveria refletir esse princípio da filosofia político-liberal e contratualista. Em Portugal, como será demonstrado a seguir, o mecanismo jurídico encontrado foi a construção de um contencioso administrativo que não levasse as causas de interesse direto do Estado (da administração pública) para serem julgadas por um outro poder (função do estado): o judiciário. A partir dessa postura, é construída em Portugal a tradição da autonomia da jurisdição administrativa, inspirada no modelo francês de Administração executiva. ${ }^{26}$

A título de exemplo, na escola Pandectística, os conceitos eram formulados em cadeia de forma a evitar a contradição dentro do sistema - do concreto para o mais abstrato; do mais abstrato para o mais concreto. Assim, um princípio (um conceito) mais abstrato - a separação dos poderes - poderia justificar a edificação de um conceito menos abstrato - a autonomia administrativa reforçada pelo contencioso administrativo do modelo francês, ou seja, a não interferência do judiciário nas questões de Estado.

\section{b. As escolas do contencioso administrativo}

Em Portugal, essas influências do liberalismo, tanto na política quanto no Direito, significaram, nas palavras de Paulo Otero, que e apesar do Estado liberal defender a neutralidade e a não intervenção na esfera da sociedade civil, esse ideário veio consolidar o afastamento da atividade administrativa do direito comum, criando, consequentemente, um direito próprio para a Administração: o Direito Administrativo. ${ }^{27}$ E justificam a correlação que o Professor Doutor José Frederico Laranjo faz entre o contencioso da Administração e as revoluções liberais. Lembrando que, como já citado em nota, esse autor foi o responsável, em Portugal, pela defesa da existência de Tribunais Administrativos com garantias análogas às dos Tribunais Judiciais.

Ressalta-se, ainda, que os posicionamentos sobre a existência e a estrutura do funcionamento do Contencioso da Administração são pronunciados em meio a um contexto acadêmico, em que três modelos são propostos (os quais influenciaram em certa medida os sistemas jurídicos) - representados a seguir pelas chamadas escolas do contencioso administrativo. Note-se que, à época (final do século XIX) em que se deu o debate e que o texto foi escrito, Portugal era governado por uma Monarquia. ${ }^{28}$

O contencioso administrativo teve, em sua origem, três escolas que propunham estruturas e funções diferentes para os órgãos incumbidos de julgar as contestações de direitos

\footnotetext{
${ }^{26}$ Sobre esse aspecto, ver: MACHADO, Jónatas E. M. Breves Considerações em torno do âmbito da Justiça Administrativa. Coimbra: Coimbra Editora. 2006.

${ }^{27}$ OTERO, Paulo. Revolução Liberal e Codificação Administrativa: In Estudos em Memória do Professor Doutor João de Castro Mendes.. Lisboa: LEX Edições Jurídicas. 1995. P. 618.

${ }^{28} \mathrm{Na}$ época da primeira edição da obra de José Frederico Laranjo, a monarquia constitucional de Portugal tinha como seu Rei Dom Luis I - Luís Filipe Maria Fernando Pedro de Alcântara António Miguel Rafael Gabriel Gonzaga Xavier Francisco de Assis João Augusto Júlio Valfando de Saxe-Coburgo-Gotha e Bragança -, segundo filho de Dona Maria II e do Rei Fernando II.
} 
entre particulares e a Administração em matéria administrativa - se essas contestações devem ser levadas à Administração, ou perante os tribunais comuns ou especiais. ${ }^{29}$

A escola reacionária ou absolutista quer que as questões que se levantem entre a Administração e os particulares em matéria administrativa sejam levadas perante o governo e por ele decididas. ${ }^{30}$

A escola radical entende que o contencioso administrativo só deve compreender as reclamações sobre o mérito, a justiça, a oportunidade de uma providência tomada pelo governo ou pela Administração discricionariamente e nos limites de seus poderes, e que toda a reclamação que se funda nos termos expressos de uma lei, decreto, regulamento, aresto deve ser levada perante os Tribunais Judiciais. ${ }^{31}$

A escola intermédia nem quer que os agentes administrativos sejam juízes em questões que eles ou seus delegados são partes, nem que tais contestações sejam levadas perante o poder judicial comum, mas sim perante os Tribunais Especiais. ${ }^{32}$

Como se percebe, as escolas propõem soluções diversas para a seguinte questão: como resolver os litígios em que são partes a Administração e os particulares, preservando a independência dos poderes (funções do Estado) e preservando, também, a imparcialidade do julgador? As propostas propõem soluções diferentes para essa problemática, umas tendendo mais para a imparcialidade, outras para a independência dos Poderes.

\section{c. $O$ contencioso administrativo em Portugal}

Parecer da Comissão de Administração Pública sobre o projeto do Código Administrativo de $1877^{33}$ se posiciona em relação ao debate doutrinário representado pelas escolas descritas anteriormente da seguinte forma:

Se como braço do poder executivo, e participando por isso da natureza daquele poder, encerra a administração elementos que a afastam do Poder Judicial, não devemos desconhecer que sobre esta consideração puramente teórica prepondera a conveniência pública que, exigindo energia e rapidez na acção administrativa, repudia o processo vagaroso que se observa nos Tribunais Judiciários.

\footnotetext{
29 LARANJO, José Frederico. Princípios e Instituições de Direito Administrativo. Coimbra: Imprensa da Universidade. 1888. P. 30.

30 LARANJO, José Frederico. Princípios e Instituições de Direito Administrativo. Coimbra: Imprensa da Universidade. 1888. P. 30.

31 LARANJO, José Frederico. Princípios e Instituições de Direito Administrativo. Coimbra: Imprensa da Universidade. 1888. P. 31.

32 LARANJO, José Frederico. Princípios e Instituições de Direito Administrativo. Coimbra: Imprensa da Universidade. 1888. P. 31.

33 Informação retirada do texto de autoria João B. Serra, intitulado As reformas da Administração local de 1872 a 1910, P. 11. Disponível em: http://analisesocial.ics.ul.pt/documentos/1223032474A8iCH0wm8Fi02HS6.pdf . Acesso em 5.4.2014.
} 
Recuando um pouco mais no tempo, mas ainda no século XIX, em Portugal, verifica-se que quando são investigados textos sobre o nascimento, a origem do contencioso administrativo, a conexão mais recorrente é com a Revolução Francesa de 1789. Veja, como exemplo, fragmento do texto de autoria de Paulo Otero ${ }^{34}$, em que é citado Mouzinho da Silveira, comentando o relatório do Decreto n. 23 , de 16 de maio de $1832^{35}$, dirigindo-se a Dom Pedro: Senhor! A mais bela descoberta moral do século passado foi, sem dúvida, a diferença de administrar e julgar. ${ }^{36}$ (...) Mais à frente no texto: $O$ citado relatório desenvolvia e aplicava esta mesma ideia dizendo que a autoridade administrativa é independente da judiciaria. Sobre esse período, Paulo Otero reflete: A Revolução Liberal de 1820 vem consagrar o entendimento francês do princípio da separação (... $)^{37}$

Entretanto, segundo o Conselheiro Fernando Azevedo Moreira, então Vice-Presidente Do Supremo Tribunal Administrativo, o nascimento do contencioso administrativo em Portugal, nos traços gerais que hoje apresenta, surgiu na sequência da revolução liberal do início do século XIX. ${ }^{38}$

Poderá assim dizer-se que a história moderna do contencioso administrativo se inaugurou em Portugal no ano de 1845 com a criação do Conselho de Estado, órgão de cúpula desta jurisdição, inspirado no modelo francês, e que incluía ainda no âmbito da sua competência funções administrativas e funções políticas.

Comentando os revezes existentes na história portuguesa acerca da adoção e limites do contencioso administrativo, Maria da Glória Ferreira Pinto Dias Garcia, relata que "A luta entre os defensores da solução francesa e os defensores da solução tradicional inicia-se e distintos modelos de justiça formal da Administração sucedem-se no sistema constitucional liberal português, oscilando entre o judicialismo tradicional e o modelo de raiz francesa." 39 Observe-se, nesse fragmento de texto, que sempre o fundamento encontrado na doutrina especializada para a adoção ou não do contencioso administrativo é o modelo liberal. Esse fundamento será mais à frente questionado.

\footnotetext{
${ }^{34}$ Paulo Otero mais à frente em seu texto faz referência à tese de Tocqueville que será apresentada aqui no tópico relativo à antítese.

35 "Por sua vez Coelho da Rocha, no ensaio sobre a história do Governo e da legislação em Portugal para servir de introdução ao Direito Pátrio - 1846 - viu os decretos de 1832 como uma reforma necessária, mas, devido à "precipitação e forma, que se lhes deu, fez com que em lugar de remédio, elas viessem antes aumentar os males públicos". É que, em vez de ter ido buscar a inspiração dentro da própria casa, se recorreu "à França e ã Inglaterra, as duas nações mais ricas da Europa". E Alexandre Herculano, não obstante a sua grande administração por Mouzinho da Silveira, considerava que o sistema de Administração Francês, que se introduziu em Portugal, foi um erro e, por isso, não admirava que ele funcionasse mal." In Catroga, Fernando. Natureza e História na fundamentação do municipalismo da Revolução Liberal ao Estado Novo (uma síntese). P. 10. Disponível em: <http://ler.letras.up.pt/uploads/ficheiros/4980.pdf>. Acesso em 5.4.2014.

${ }^{36}$ OTERO, Paulo. Revolução Liberal e Codificação Administrativa: In Estudos em Memória do Professor Doutor João de Castro Mendes. Lisboa: LEX Edições Jurídicas. 1995. p. 619.

37 OTERO, Paulo. Revolução Liberal e Codificação Administrativa: In Estudos em Memória do Professor Doutor João de Castro Mendes. Lisboa: LEX Edições Jurídicas. 1995. p. 619.

${ }^{38}$ Anais do III CONGRESSO INTERNACIONAL DO CENTRO LATINO-AMERICANO DA ADMINISTRAÇÃO PARA O DESENVOLVIMENTO. Disponível em: <http://www.stadministrativo.pt/Lportuguesa/relint/relatorios/CLAD/relatorios_clad1998.html>. Acesso em: 5/7/2014.

${ }^{39}$ GARCIA, Maria da Glória. Da Justiça Administrativa em Portugal. Sua Origem e Evolução. Lisboa: Universidade Católica Editora. 1994. P. 394.
} 
Em trabalhos mais atuais sobre o contencioso administrativo em Portugal, Marcello Caetano verifica que: outra característica do nosso sistema administrativo é a existência dos tribunais administrativos, que não são tribunais especiais do Poder Judicial, mas órgãos da própria Administração. Mais à frente, o autor justifica a adoção do modelo: se os actos administrativos fossem susceptíveis de discussão nos tribunais judiciais, teríamos o poder judicial a intervir na Administração, a condicionar os seus passos, a impor a sua interpretação da lei, reduzindo-a a uma subordinação incompatível com o poder. ${ }^{40}$ Tratando, agora, da garantia administrativa ${ }^{41}$, o autor explica que tal deve-se ao princípio da separação das duas funções, administrativa e judiciária. ${ }^{42}$

Fica, então, a questão: qual a origem desse sistema? Será a Revolução Francesa? Relembra-se que o objetivo do trabalho aqui proposto não é discorrer sobre o contencioso administrativo em Portugal ou no Brasil, mas identificar na literatura especializada as raízes políticas ou ideológicas desse mecanismo jurídico.

\section{d. $O$ contencioso Administrativo no Brasil}

No Brasil, durante os dois Impérios, houve o contencioso administrativo, no modelo francês. Nesse caso, tal função era decidida em última instância pelo Poder Moderador. Nesse sentido ver Constituição do Império de 1824 e Regimento n. 124, de 5 de fevereiro de $1842 .{ }^{43}$

A partir da Constituição de 1889, segue-se o sistema Inglês e não o Francês sobre o contencioso administrativo - o chamado sistema da unidade de jurisdição, também conhecido como sistema de monopólio da jurisdição. É um sistema próximo daquele classificado como radical, por José Frederico Laranjo em linhas acima. Nesse sistema, apenas os órgãos do Judiciário exercem a função jurisdicional e proferem decisões com o caráter da definitividade. Mesmo as raríssimas exceções previstas na Constituição brasileira de $1988^{44}$, conferindo essa função ao congresso nacional, não servem para desfigurar o monopólio da jurisdição pelo Judiciário. $O$ fundamento do sistema da unidade de jurisdição no Brasil possui sede constitucional, no inciso XXXV, do art. 5, da Constituição em referência. ${ }^{45}$

Segundo Ana Rita Antunes, a primeira consagração do modelo administrativo característico de um Estado Social de Direito ocorreu em 1891, com a adopção do sistema de jurisdição única, segundo o qual todos os litígios, independentemente da parte envolvida (demonstração do passo dado no sentido da igualdade de fato), seriam resolvidos perante o poder Judi-

\footnotetext{
${ }^{40}$ CAETANO, Marcello. Manual de Direito Administrativo. Coimbra: Almedina. 2010. P. 38.

${ }^{41}$ (...) consiste no privilégio, excepcionalmente concedido pela lei a determinadas hierarquias ou categorias de agentes administrativos, de as aç̧ões criminais nascidas de factos praticados no exercício das suas funções e com elas relacionados não poderem prosseguir contra eles sem prévia autorização do Governo. In CAETANO, Marcello. Manual de Direito Administrativo. Coimbra: Almedina. 2010. P. 38.

${ }^{42}$ CAETANO, Marcello. Manual de Direito Administrativo. Coimbra: Almedina. 2010. P. 36, 37 e 39.

${ }^{43}$ Para um maior aprofundamento da História do Direito Administrativo no Brasil, ver: De Paula, Edylcéia Nogueira, em artigo intitulado O Contencioso Administrativo. Disponível na Biblioteca do Senado Federal Brasileiro, em: http://www2.senado.leg.br/bdsf/bitstream/handle/id/181131/000365783. pdf?sequence=3. Acesso: 1/7/2014.

${ }^{44} \mathrm{O}$ sistema de jurisdição desportiva e o habeas data servem de exemplos às essas exceções.

${ }^{45}$ CARVALHO FILHO, José dos Santos. Manual de Direito Administrativo. 25 ed. São Paulo: Editora Atlas. 2012. P. $1003 / 1004$
} 
ciário. Assim, as causas que envolvessem diretamente atos da Administração seriam da responsabilidade das instâncias do Poder Judiciário. Não há, portanto, espaço para falar-se em contencioso administrativo no Brasil, nos mesmos moldes em que ele se desenvolve em França, não sendo, contudo, de considerar que há uma impossibilidade de conjugação entre "contencioso administrativo e jurisdição una". ${ }^{46}$

\section{A ANTÍTESE - O CONTENCIOSO ADMINISTRATIVO E A SUA ORIGEM NO REGIME ABSOLU- TISTA FRANCÊS (O ANTIGO REGIME)}

Alexis de Tocqueville (1805 a 1859) ${ }^{47}$, comentando o regime absolutista francês, diz que não havia país europeu em que os tribunais comuns dependessem menos do governo do que na França, mas, também, não havia quase nenhum em que os tribunais de exceção estivessem mais em uso. Como o rei não exercia quase nenhum poder sobre os juízos, já que não podia demiti-los ou transferi-los, sonegava-lhes o conhecimento dos assuntos que envolviam diretamente seu poder, criando, para seu uso particular, ao lado dos magistrados comuns, uma espécie de tribunal mais independente, que apresentasse a seus súditos alguma aparência de justiça sem fazê-lo temer por suas decisões. ${ }^{48}$

Uma das teses que Tocqueville desenvolve em uma de suas obras - O Antigo Regime - é de que a origem do contencioso administrativo é a estratégia do rei francês absolutista descrita no parágrafo anterior. Tese essa cujos principais argumentos serão expostos na sequência.

Alguns exemplos de éditos franceses da época absolutista ilustram a transferência das lides envolvendo a Administração e particulares (súditos) para os chamados intendentes e conselhos, órgãos vinculados diretamente ao monarca e afastando-as do conhecimento das cortes e dos juízes. Segue trecho de um édito, transcrito por Tocqueville, em sua obra referida, que ilustra bem esse estratagema:

(...) Ordena ademais Sua Majestade que todas as contestações que puderem surgir quanto à execução do presente decreto, circunstâncias e dependências, sejam apresentadas ao intendente para serem julgadas por ele, salvo recurso ao Conselho. Proibimos nossas Cortes e Tribunais de tomarem conhecimento delas. ${ }^{49}$

\footnotetext{
46 Disponível em: http://psicanalise-do-contencioso.blogspot.pt/2010/10/sistema-do-contenciosoadministrativo.html

${ }^{47}$ Dois autores abordaram no século XIX, do ângulo do pensamento social, a problemática da pobreza: Karl Marx (1818-1883) e Alexis de Tocqueville (1805-1859). Ao passo que o primeiro elaborou o arquétipo interpretativo socialista (banindo a livre iniciativa e apregoando o fim do capitalismo), o segundo construiu o arquétipo liberal (alicerçado na livre iniciativa e pressupondo consequentemente o capitalismo). Alexis de Tocqueville recebeu forte influência de Benjamin Constant de Rebecque e de Guizot. Vivenciou parte da Revolução Francesa, deixando registrada sua experiência em Lembranças de 1848. In Ricardo Velez Rodrigues. O PENSAMENTO DE ALEXIS DE TOCQUEVILLE (1805-1859) EM FACE DA POBREZA: UMA ABORDAGEM LIBERAL. Disponível em <http://pensadordelamancha.blogspot.pt/2011/05/o-pensamento-de-alexis-de-tocqueville.html>. Acesso em 19.4.2014.

48 TOCQUEVILE, Alexis de. O Antigo Regime e a Revolução. Tradução de Rosemary Costhek Abílio. São Paulo: Martins Fontes. 2009. P. 61.

${ }^{49}$ TOCQUEVILE, Alexis de. O Antigo Regime e a Revolução. Tradução de Rosemary Costhek Abílio. São Paulo: Martins Fontes. 2009. P. 64.
} 
Relata, ainda, que na época a maioria das questões litigiosas sobre impostos, controle e transporte de mercadorias, dos veículos de uso público, relativas à navegação fluvial, dentre outras, se resolvia perante essa estrutura paralela formada pelo intendente do Rei e pelos Conselhos (uma estrutura Administrativa). As justificativas para a existência dessa estrutura paralela são pragmáticas. Enquanto o juiz comum está subordinado a regras fixas, o conselho pode derrogar tais regras com um objetivo útil (essas informações são apresentadas por Tocqueville e oriundas de documentos da época). Ainda, encontra-se na obra o Antigo Regime e a Revolução algumas citações ou reproduções de documentos da época em que a autoridade real retira da justiça comum o conhecimento de lides de natureza comum, mas que envolviam partes consideradas estratégicas segundo o regime absolutista. Sobre esse movimento, Tocqueville, adverte: a intervenção da justiça na administração prejudica apenas os negócios ao passo que a intervenção da administração na justiça deprava os homens e tende a tornalos simultaneamente revolucionários e servis. ${ }^{50}$ Lembra-se que Tocqueville está preocupado em investigar traços institucionais do Antigo Regime que foram preservados pela Revolução.

Tocqueville relata que em pelo menos uma das dez constituições perpétuas editadas no antigo regime francês, encontra-se uma norma que expressamente diz que nenhum agente da administração pode ser processado perante os tribunais comuns sem que a ação judicial tenha sido expressamente autorizada pela Administração real. A partir disso critica os autores administrativistas que costumam classificar como uma das grandes conquistas de 1789 o privilégio que tal prescrição concede aos ideários liberais. Mas, adverte o autor (que foi político - deputado de 1839 a 1951 - também, em um dos períodos revolucionários): mas nisso se enganam igualmente, pois a monarquia (absolutista) não tinha menos cuidado do que hoje em poupar os funcionários do dissabor de terem de confiar-se à justiça como simples cidadãos. ${ }^{51} \mathrm{E}$ mais à frente distingue: antes da Revolução, o governo só podia acobertar seus agentes recorrendo a medidas ilegais e arbitrarias, ao passo que depois ele pôde legalmente deixalos violar as leis. ${ }^{52}$

\section{- CONSIDERAÇÕES FINAIS}

Procura-se concluir esse trabalho lembrando a metodologia proposta por Hobsbawm, segundo a qual: seu leitor ideal seria aquele construtor teórico, aquele cidadão culto e inteligente, que não tem uma simples curiosidade sobre o passado, mas que deseja compreender como e porque o mundo veio a ser o que é hoje, e para onde se dirige. ${ }^{53}$ Busca-se demonstrar a importância do estudo e do método histórico (uma reconstrução em retrospectiva do passado) para compreender as instituições de maneira ampla e as do Direito em específico. Explica-se: ao estudar o contencioso administrativo português por meio dos clássicos da época,

\footnotetext{
50 TOCQUEVILE, Alexis de. O Antigo Regime e a Revolução. Tradução de Rosemary Costhek Abílio. São Paulo: Martins Fontes. 2009. P. 64.

51 TOCQUEVILE, Alexis de. O Antigo Regime e a Revolução. Tradução de Rosemary Costhek Abílio. São Paulo: Martins Fontes. 2009. P. 64.

52 TOCQUEVILE, Alexis de. O Antigo Regime e a Revolução. Tradução de Rosemary Costhek Abílio. São Paulo: Martins Fontes. 2009. P. 64.

${ }^{53}$ HOBSBAWM, Eric. J. A Era das Revoluções - 1789 - 1848. São Paulo: Paz e Terra. 2012. P. 15.
} 
impregnados de uma metodologia dogmática que buscava construir teorias sobre a normatividade do Direito a partir de um encadeamento de conceitos (ou de uma rede de conceitos em uma linguagem mais atual), pode-se chegar a uma conclusão que o modelo de contencioso administrativo em Portugal deriva de um conceito mais abstrato e liberal, que é o da separação dos poderes (funções do Estado). No entanto, quando as origens históricas, os documentos de época são buscados, ainda que por intermédio da literatura histórica ou sociológica, desvenda-se que tal sistema jurídico é muito mais teleológico, muito mais pragmático do que, do contrário, poder-se-ia imaginar.

Ficou, na antítese, demonstrado que o contencioso administrativo francês foi uma estratégia do absolutismo monárquico que vigorou naquele país, e como tal (uma estratégia) decorre de uma lógica finalística, típica da política, exterior, portanto (ao menos para a maioria do pensamento jurídico), ao próprio sistema do Direito. Por exemplo, quando José Frederico Laranjo classifica e analisa os modelos do contencioso administrativo, ele, o autor, está muito mais preocupado em saber em que medida tais modelos encaixam em um conceito mais elevado e mais abstrato, o de separação de poderes. É essa análise derivativa e conceitual que marca a lógica do Direito na época em que a sistematização de José Frederico Laranjo foi realizada (século XIX). Ao passo que a análise da história e da sociologia feita por Tocqueville desvenda a lógica finalística, de "meio-fins" do contencioso administrativo francês, que inspirou o modelo português. Quando o monarca absolutista francês arquiteta um mecanismo que conduz as causas de relevo para o Estado para o intendente e para o Conselho - órgãos dependentes de seu poder - ele, o monarca, está construindo um sistema que lhe é útil, útil aos fins que pretende, que é o de governar sem a interferência de estruturas independentes. Ele, o monarca, não está preocupado em derivar tal mecanismo de um sistema conceitual, mas sim com a utilidade, que é sempre pragmática, desse mecanismo jurídico.

\section{REFERÊNCIAS}

ALMEIDA, Maria Júlio de. Colaboração de Rui Manuel de Figueiredo Marcos. 5. Ed. Rev. e Atual. Coimbra: Almedina. 2011.

CAETANO, Marcello. Manual de Direito Administrativo. Coimbra: Almedina. 2010

CARVALHO FILHO, José dos Santos. Manual de Direito Administrativo. 25 ed. São Paulo: Editora Atlas. 2012.

. O Contencioso Administrativo no Brasil (Revista de Direito da Procuradoria-Geral de Justiça do Rio de Janeiro, n.8, 1979).

CATROGA, Fernando. Natureza e História na fundamentação do municipalismo da Revolução Liberal ao Estado Novo (uma síntese). Disponível em: http://ler.letras.up.pt/uploads/ficheiros/4980.pdf. Acesso em 5.4.2014.

DE PAULA, Edylcéia Nogueira. O Contencioso Administrativo. Disponível na Biblioteca do Senado Federal Brasileiro, em: http://www2.senado.leg.br/bdsf/bitstream/handle/id/181131/000365783.pdf?sequence=3. Acesso: 1/7/2014

DI PIETRO, Maria Sylvia Zanella. Direito administrativo, São Paulo, Atlas, 1993. 
GARCIA, Maria da Glória. Da Justiça Administrativa em Portugal. Sua Origem e Evolução. Lisboa: Universidade Católica Editora . 1994.

HOBSBAWM, Eric. J. A Era das Revoluções - 1789 - 1848. São Paulo: Paz e Terra. 2012.

LARANJO, José Frederico. Princípios e Instituições de Direito Administrativo. Coimbra: Imprensa da Universidade. 1888.

LARENZ, Karl. Metodologia da Ciência do Direito. Tradução de José Lamego. 3 ed. Lisboa: Fundação Calouste Gulbenkian. 1997.

MACHADO, Jónatas E. M. Breves Considerações em torno do âmbito da Justiça Administrativa. Coimbra: Coimbra Editora. 2006

MARCOS, Rui Manuel de Figueiredo. História da Administração Pública, Relatório sobre o Programa, o Conteúdo e os Métodos de Ensino. Coimbra: Editora Coimbra. 2005.

MEIRELLES, Hely Lopes. Direito administrativo brasileiro, São Paulo, Malheiros, 1993.

MOREIRA, Fernando Azevedo. Anais do III CONGRESSO INTERNACIONAL DO CENTRO LATINOAMERICANO DA ADMINISTRAÇÃO PARA O DESENVOLVIMENTO. Disponível em: http://www.stadministrativo.pt/Lportuguesa/relint/relatorios/CLAD/relatorios_clad1998.html. Acesso em: 05 jul. 2014.

NEVES, A. Castanheira. Metodologia Jurídica. Problemas Fundamentais. Reimpressão. Coimbra: Coimbra Editora. 2013.

OTERO, Paulo. Revolução Liberal e Codificação Administrativa: In Estudos em Memória do Professor Doutor João de Castro Mendes. Lisboa: LEX Edições Jurídicas. 1995.

RODRÍGUES, Ricardo - Velez. O Liberalismo Francês: a tradição doutrinária e sua influência no Brasil. P 33. Disponível em: http://www.cdpb.org.br/liberalismo_frances_velez.pdf. Acesso em: 2.4.2014.

. O PENSAMENTO DE ALEXIS DE TOCQUEVILLE (1805-1859) EM FACE DA POBREZA: UMA ABORDAGEM LIBERAL. Disponível em http://pensadordelamancha.blogspot.pt/2011/05/o-pensamento-de-alexis-de-tocqueville.html. Acesso em 19.4.2014.

SERRA, João B. As reformas da Administração local de 1872 a 1910. Disponível em: http://analisesocial.ics.ul.pt/documentos/1223032474A8iCH0wm8Fi02HS6.pdf . Acesso em 5.4.2014.

TOCQUEVILLE, Alexis de. O Antigo Regime e a Revolução; Tradução de Rosemary Costhek Abílio. São Paulo: Editora WMF Martins Fontes. 2009. 